\title{
CALENDAR OF COMPUTER-CHESS EVENTS
}

\section{3}

\section{July 1-2}

The Advances in Computer Chess 7 Conference, to be held in Maastricht, The Netherlands.

Details: Jaap van den Herik, Department of Computer Science, University of Limburg, P.O. Box 616, 6200 MD Maastricht, The Netherlands.

[See also page 174 of the September 1992 issue, page 65 of the March 1993 issue and page 117 of this issue.]

\author{
August 2-6 \\ Uniform Platform Computer-Chess Tournament, to be held in London, UK. \\ Details: Don Beal, Department of Computer Science, Queen Mary and Westfield College, Mile End Road, \\ London E1 4NS, UK. \\ [See also pages 173-174 of the September 1992 issue and page 64 of the March 1993 issue.]

\section{October 31 - November 7} \\ The $12^{\text {th }}$ World Microcomputer Chess Championship, to be held in Munich, Germany. \\ Details: David Levy, 89, Constantine Road, London NW3 2LP, UK. \\ [See also below and next page of this issue.]
}

\section{THE 1993 WORLD MICROCOMPUTER CHESS CHAMPIONSHIP}

\author{
ICCA Communication \\ by David Levy
}

The $12^{\text {th }}$ World Microcomputer Chess Championship will take place in Munich, Germany from October $31^{\text {st }}$ to November $7^{\text {th }}, 1993$. The principal sponsor is Computer-Schach \& Spiele. When subscribing, please use a copy of the entry form on the next page.

The tournament will be played in two groups, the Software Group and the Manufacturers' Group. The Software Group will be a 7-round Swiss System tournament. All entries apart from dedicated chess computers will take part in the Software Group.

The Manufacturers' Group will contain only chess computers submitted by manufacturers who have already sold chess computers in the shops. Each manufacturer may enter up to 4 machines, of which one machine may, at the manufacturer's discretion, use unlimited computing power. The sum of the dimensions of a machine in this group (width + breadth + height) may not be more than the maximum sum of dimensions of all chess computer on the market on September $30^{\text {th }}, 1993$.

The format of the tournament in this group will be announced when the number of entries is known. It will be an all-play-all format, with the number of rounds being as many as is practical for the number of entries.

The winner of the Software Group will play a match against the winner of the Manufacturers' Group for the title of "absolute World Microcomputer Chess Champion". Other World Championship titles shall be awarded in the Manufacturer, Software and Amateur categories. 